4 Gabbay KH. The sorbitol pathway and the complications of diabetes. $N$ Engl J Med 1973;288:831-6.

${ }^{5}$ Beisswenger PJ, Spiro RG. Human glomerular basement membrane: chemical alteration in diabetes mellitus. Science 1970;168:596-8.

- Bunn HF, Haney DN, Gabbay KH. Further identification of the nature and linkage of the carbohydrate in hemoglobin $\mathrm{A}_{1 \mathrm{C}}$. Biochem Biophys Res Commun 1975;67:103-9.

${ }^{7}$ Bunn HF, Haney DN, Kamin S, Gabbay KH, Gallop PM. The biosynthesis of human hemoglobin $A_{1}$ : slow glycosylation of hemoglobin in vivo. J Clin Invest 1976;57:1652-9.

${ }^{8}$ Marks PA. Methods in enzymology vol 9. New York: Academic Press, 1966:131-5.

${ }^{9}$ Beutler E. A manual of biochemical methods. New York: Grune and Stratton, 1971:58.

${ }^{10}$ Bueding E, MacKinon JA. Studies of the phosphoglucose isomerase of Schistosoma mansoni. J Bio Chem 1955;215:507-13.

11 Trivelli LA, Ranney HM, Lai H. Hemoglobin components in patients with diabetes mellitus. $N$ Engl J Med 1971; 284:353-7.

\section{Polly-pica treated by xerography}

In these days of photocopying it is difficult to know why so many reprints are requested. Below is one reason: it concerns our article which appeared at the front of this journal in 1977..$^{1}$ Extracts of a letter received from the PHLS Lab (Preston) are reproduced below.

"In this laboratory until the $J$ Clin Pathol is sent to the binders they are kept well hidden. Recently, contrary to normal practice, two years' issues prior to binding were lent to an MLSO preparing for her examinations. She returned them after two days, white-faced and solemn with the following story:

Her pet parrot (Fig.), a bird that seldom flies or even walks, had been left alone in the room with the journals. On her return a half-eaten apple, a vandalised plant, and the front of $J$ Clin Pathol 1977;30:1-12 were spread over the carpet.

May we please therefore request a reprint of your article.

As well as her interest in gastrointestinal pathology, "Polly" can whistle Col Bogey and blow raspberries. Her owner Mrs Catherine Seed sends her apologies."

We thought you would like to know that your journal is so widely appreciated and

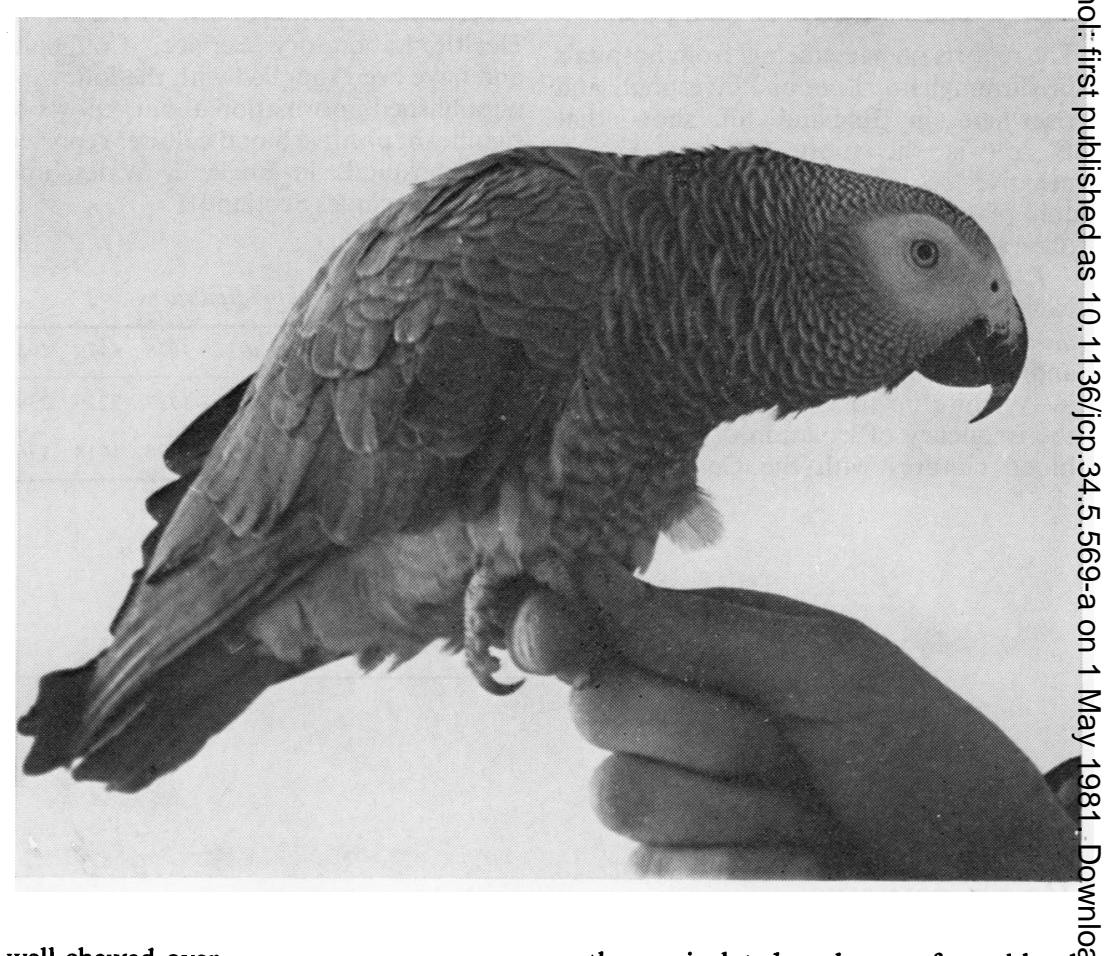

well chewed over.
AB PRICE* DR DAVIES $\dagger$

*Northwick Park Hospital, Harrow †St Thomas' Hospital, London SEI

\section{Reference}

1 Price AB, Davies DR. Pseudomembranous colitis. J Clin Pathol 1977;30:1-12.

Aetiological agents and laboratory diagnosis of bacteraemic shock

In your report of a symposium on septic shock, ${ }^{1}$ Dr Shanson claimed that "during the last 30 years in Britain the incidence of bacteraemias due to.Gramnegative organisms has greatly increased." He gave the numbers of isolates from blood cultures during 1977 in a district hospital in London; Escherichia coli was the most frequent cause of bacteraemia.

In Ayrshire we have found that during the past two years $E$ coli has decreased in importance as a cause of bacteraemia, probably due to increasing use of short courses of perioperative antibiotics for gastrointestinal and pelvic surgery. Thus from 1974-8, $E$ coli was the most frequent pathogen isolated each year from blood cultures in Ayrshire. In 1979 the most ${ }_{\varrho}^{\Phi}$ frequent pathogen was Staphylococcus aureus, which was isolated from 27 음 $(26 \%)$ of 102 patients with bacteraemia, $E$ coli from $22 \%$, and other coliform species from $14 \% .^{2}$ In 1978 the most frequent pathogens were $E$ coli from $28 \%$ coliform species from $20 \%$, and Staph aureus from $15 \%$. Isolates of Bacteroides species decreased from $9 \%$ in 1978 to $5 \%$ in 1979. The decrease in Enterobacteria-윽 ceae and Bacteroides species was associ- $₹$ ated clinically with fewer cases of bac-을

CONSTANCE AC ROSs을 Microbiology Laboratory, Ayrshire Central Hospital, or Irvine, $\mathrm{O}$ Ayrshire KA12 8SS

References

${ }^{1}$ Shanson DC. Septic shock: aetiological agents and laboratory diagnosis of bacteraemic shock. J Clin Pathol 1980; 33:888-9.

2 McGill RET, Ross CAC. Septicaemia in Ayrshire, 1979. Communicable diseases Scotland 1980;37:7-8. teraemic shock. 